\title{
An Overview on the Next Generation Li-ion batteries
}

\section{AVINASH PANDEY ${ }^{1}$}

${ }^{1}$ Madan Mohan Malaviya University of Technology

November 2, 2020

\begin{abstract}
Lithium-ion batteries have been the nucleus of the digital-modernization,especially when acknowledging the exponential rise in the digital-dependency of society on mobile devices. As they play such a vital role, over the years various efforts have been made to increase there capacity, cyclability and battery life with higher safety measures. At present,LiCoO2 cathode batteries with carbonaceous anode and LiPF6/EMC electrolyte is the most commonly used Li-ion battery. However the toxicity of Co,low cyclability of carbon and the inflammable nature of EMC demand the next generation Li-ion battery with enhanced performance and safety measures to take its place commercially to meet the high demand of the society which is possible at nanoscale using LiFePO4 and silicon-nanowires as the electrodes with an inorganic electrolyte(fluid SO2) that is incombustible in nature. The following content briefly explains the challenges faced by the current generation of Lithium-ion batteries and the recent progress made to tackle the said problems.
\end{abstract}

\section{Hosted file}

Final-2.pdf available at https://authorea.com/users/372065/articles/490223-an-overview-onthe-next-generation-li-ion-batteries 